\title{
A sociabilidade juvenil e a rua: novos conflitos e ação coletiva na cidade
}

\author{
MARILIA PONTES SPOSITO
}

RESUMO: As novas formas de sociabilidade que se gestam entre os jovens, moradores dos bairros periféricos das grandes cidades, nascem principalmente da socialização no mundo da rua, suas esquinas e pontos de encontro, onde desenvolvem relações de amizade e lazer, enfrentam os mecanismos da violência urbana e vivem, na luta pela sobrevivência, o confronto diário com os aparelhos repressivos. Neste espaço buscam construir identidades coletivas e diversas modalidades de sociabilidade. Algumas formas de ação reúnem atividades expressivas em torno da música e da dança de rua, como o RAP - Rhythm and Poetry - na periferia de São Paulo e outras cidades brasileiras. Agrupando jovens, em sua maioria negros e pobres, o RAP por meio da dança e da música, praticadas sobretudo nas ruas, denuncia a exclusão cultural, a violência policial e critica a discriminação sofrida no mundo do trabalho e da escoIa.

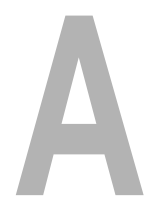

cidade, "espaço-tempo" e não apenas projeção de uma estrutura social no espaço, como afirmou Lefebvre (1978), revela formas e conteúdos de relações sociais diversas. A produção, a socialização, o consumo e as práticas culturais incidem sobre usos diferenciais do espaço e espelham os ritmos desiguais que caracterizam não só as relações entre as classes, mas a dinâmica das gerações e dos grupos de idade, as relações entre os gêneros, os ciclos de vida no trabalho e no lazer. Enfim, conjunto intenso de relações que projetam em um só presente diversas temporalidades, a cidade pode se tornar, também, a expressão de conflitos multifacetados, capazes de oferecer novas possibilidades de apropriação do tecido urbano.

Alguns estudos analisaram São Paulo, seu centro e suas periferias, privilegiando o ponto de vista dos conflitos e da ação coletiva que envolveram a

\section{UNITERIMOS:}

juventude, sociabilidade de rua, ação coletiva, cultura afro-americana.

Trabalho apresentado no Simpósio Problemas Ambientais Rurais e Urbanos da América Latina no $48^{\circ}$ Congresso Internacional de Americanistas. Estocolmo, 4 a 9 de julho de 1994.

Professora da Faculdade de Educação da USP 
${ }^{1}$ Vários trabalhos reconstituíram, sob perspectivas diversas, os movimentos populares da cidade de São Paulo. Alguns detiveramse no exame das manifestações que surgiram a partir da década de 70 , examinando problemas diversos como moradia, saúde, educação, entre outros. A este respeito consultar (Camargo, 1976; Singer \& Brant, 1980; Gohn, 1982, 1985, 1991; Krischke, 1984; Brant, 1989; Jacobi, 1989; Kowarick, 1988; Sposito, 1993a).

${ }^{2} \mathrm{O}$ tema da juventude enquanto agente revitalizador aparece nas formulações de Mannheim (1954).

${ }^{3} \mathrm{O}$ trabalho de Márcia Regina da Costa analisa os "carecas do subúrbio", outra modalidade de ação coletiva de jovens na cidade de São Paulo(Costa, 1993). constituição dos sujeitos e atores sociais. A cidade foi então concebida a partir de suas novas formas de organização, nascidas além do mundo das fábricas e das empresas. Os denominados movimentos populares de base urbana, mais visíveis a partir dos anos 70, ao demandarem equipamentos de consumo coletivo, protagonizaram modos diferenciais de percepção de necessidades não satisfeitas, concepções particulares sobre o uso do espaço, exprimiram potencial de inovação cultural, exigindo, ao mesmo tempo, o reconhecimento de direitos e um outro patamar na qualidade de vida urbana ${ }^{1}$.

Mas cenários diversos de conflitos e de ações coletivas aparecem nos anos 80 e início da década atual, trazendo outros atores, formas de apropriação e uso do espaço urbano, redes de sociabilidade e novas imagens da conflitividade social na cidade. Nesta conjuntura, o tema da juventude - em especial dos jovens filhos de trabalhadores - torna-se mais visível, revestido de novas indagações, podendo ser analisado sob vários aspectos.

Para aqueles investigadores interessados no exame das ações coletivas e das lutas sociais, o tema da juventude adquire visibilidade, estruturando várias questões. Ao lado de um certo refluxo das mobilizações de base popular que ocorreram e ainda são observadas nos bairros periféricos de cidades brasileiras como São Paulo, percebe-se que esta forma de constituição da ação coletiva tem pouco sensibilizado os setores jovens. Verifica-se, também, que outros canais da prática, como os partidos e sindicatos, ressentem-se de uma renovação geracional efetiva, em que o jovem poderia aparecer como elemento revitalizador do conflito e, desse modo, possibilitando a própria continuidade da ação coletiva ${ }^{2}$.

Ruas e praças da cidade são ocupadas pela presença de incontáveis agrupamentos coletivos juvenis, estruturados a partir de galeras, bandos, gangues, grupos de orientação étnica, racista, musical, religiosa ou as agressivas torcidas de futebol. Muitas vezes a violência sem significação aparente surge como parceira inseparável dessas manifestações, que ora se exprimem nos bairros periféricos, ora se deslocam para o centro da cidade. Percebe-se uma nova apropriação do espaço urbano, que desafia o entendimento e exige uma aproximação mais sistemática para sua compreensão.

Este artigo procura examinar uma dentre as várias manifestações do agir coletivo juvenil no mundo urbano, escolhendo o RAP - Rhythm and Poetry - rapidamente difundido nos bairros e ruas da periferia pobre da cidade de São Paulo, no final dos anos 80. Este tipo de expressão artística e musical, aliado ao break (dança de rua) e ao grafite, constitui o movimento hip-hop que, ao aglutinar pequenos grupos a partir dos 14 anos de idade, contempla questões importantes para a análise da sociabilidade juvenil no espaço urbano e suas formas de agir, apontando outras imagens possíveis da identidade coletiva e do conflito social na cidade ${ }^{3}$.

\section{Novos rumos da sociabilidade juvenil no espaço urbano}

O tema da juventude e sua definição, sempre revestida de um cará- 
ter histórico-social, exige o estabelecimento de algumas delimitações. Inicialmente, pode-se considerar que este momento da vida é traduzido pelo intervalo - cuja variação temporal é histórica - entre a posse de condições de reprodução biológica (sexual) e de produção social (maturidade física e mental para o trabalho) e o reconhecimento por parte da sociedade de sua habilitação plena para o desempenho dessas atividades na vida adulta (Rama, 1990). Por essas razões, a caracterização do jovem deve ser traçada sob o ponto de vista relacional, ou seja, a partir de uma forma peculiar de relação que ele mantém com o mundo adulto e, conseqüentemente, de sua busca de distância do universo infantil.

Procurando não reter a noção destituída de seus atributos mais concretos, torna-se necessário, também, estabelecer alguns recortes e privilegiar, para efeitos de análise, os jovens de extração trabalhadora, parte significativa do fenômeno mais geral da juventude. Por essas razões admite-se a natureza dupla do processo que os caracteriza: de um lado a exclusão social, decorrente das determinações advindas da situação de classe, e de outro as peculiaridades que decorrem da condição geracional, enquanto grupo de idade.

Os anos 80 em centros metropolitanos como São Paulo significaram a convivência com a recessão, níveis altos de desemprego e o empobrecimento, processos que afetaram, principalmente, os setores mais miseráveis da sociedade (Lopes \& Gottschalk, 1990) ${ }^{4}$.

Mas as implicações desta situação para o exame das questões relativas aos jovens (15 a 24 anos) são múltiplas e diversificadas. Durante a década de 80 observa-se o envelhecimento populacional ao lado de uma distribuição diferenciada dos setores jovens no interior dos agrupamentos sócio-econômicos, concentrando-se nos estratos de menor renda e piores condições de vida: na região metropolitana de São Paulo, em 1990, a população com menos de 18 anos corresponde a $35,7 \%$ dos indivíduos, mas nos setores mais pobres chega a $45 \%$ (Fundação Seade, 1993) $)^{5}$.

A absorção dos jovens pelo mercado de trabalho também comporta oscilações no último decênio, em seus momentos de maior recessão. Portadora de índices de escolaridade mais altos do que seus pais, esta população, ao apresentar credenciais escolares valorizadas pelo jogo do mercado, pode estar mais protegida do desemprego no momento das crises, que atingiriam, de forma mais intensa, a população adulta (Madeira \& Bercovich, 1992) ${ }^{6}$. Mesmo assim, torna-se importante considerar que o fantasma do desemprego não deixa de estar presente, embora suas conseqüências sejam mais atenuadas sobre a mão de obra juvenil. Em termos gerais, a estreiteza do mercado de trabalho pela escassa oferta de novos postos - e a baixa remuneração, expressa na perda crescente do poder aquisitivo dos salários, afetam as expectativas e comportamentos desta faixa etária.

Sob a ótica geracional vários autores já apontaram alguns elementos caracterizadores da condição juvenil que merecem ser retomados. A busca de autonomia, em redefinição constante frente aos laços de dependência com a
${ }^{4}$ Para Lopes \& Gottschalk, é preciso considerar a heterogeneidade de situações de pobreza e o impacto diferenciado da conjuntura sobre a mesma (1990). Os ciclos recessivos tendem a afetar mais rapidamente as condições de vida das famílias que se situam entre os segmentos mais miseráveis. Com a recessão, em 1990, as taxas de desemprego das famílias mais pobres na Grande São Paulo chegam a $19 \%$, ao passo que a média da região é de $9,6 \%$ (Fundação Seade, 1993).

${ }^{5}$ Não obstante a constante incorporação da população jovem e adolescente na PEA (População Economicamente Ativa), também ocorre um envelhecimento na sua estrutura etária durante os anos 80, em contraste com a juvenilização observada no decênio anterior. Este envelhecimento decorre não só do refluxo da "onda jovem" da década de 70 , mas do alargamento da faixa que caracteriza o início da idade adulta (25-35 anos). Para Madeira e Bercovich a noção de "onda jovem" significa o alargamento das faixas etárias de 15-24 anos no conjunto da população brasileira como decorrência de três fatores combinados: fecundidade, mortalidade e migrações. Após o refluxo da onda jovem nos anos 80 , observa-se que os primeiros 5 anos da década de 90 trazem novamente este fenômeno no estado de São Paulo. Em termos relativos 
as autoras apontam para o "crescimento de $46 \%$ e $51 \%$ respectivamente nas décadas de 60 e 70 e somente 8 , $6 \%$ durante os anos 80 , devendo voltar a crescer $34 \%$ na próxima década" (Madeira \& Bercovich, 1992, p. 6).

${ }^{6}$ Os dados sobre o trabalho de crianças e adolescentes da região metropolitana de São Paulo indicam efeitos diferenciais da crise econômica em seus picos recessivos sobre a mesma faixa etária: o contingente de crianças e adolescentes ativos (10 a 17 anos) é mais afetado nas crises ou na desaceleração do que o conjunto da PEA (1981/1984, 1986/ 1988). Mas, ao mesmo tempo, essa parcela é a que mais rapidamente reage às condições favoráveis do mercado (1984/1986). No período posterior a 1986 os adolescentes (15 a 17 anos) foram os menos afetados pelos ciclos recessivos (Cervini \& Burger, 1991). família, e a transitoriedade constituem elementos estruturadores da sociabilidade juvenil (Braslawsky, 1985). Mas a transitoriedade nos remete a uma formulação já clássica de Mannheim que é a idéia de marginalidade, entendida como isolamento relativo frente aos centros de poder, como capacidade de estranhamento e de tomar distância das amarras colocadas pela estrutura social (Mannheim, 1954). Essa dimensão produz, também, situações de liminaridade, traduzidas na contínua possibilidade de escolhas, na vivência de situações limite que podem resultar em alternativas que negam expectativas, regras e modelos dominantes de ordem e normalidade (Sposito, 1992; 1993b).

Este "estranhamento" cria duas outras modalidades de reconhecimento da condição juvenil, traduzidas no estado de "disponibilidade" e de "insegurança" frente ao futuro (Rama, 1990). Por essas razões as dimensões excludentes, quer sejam elas derivadas da situação de classe ou das determinações geracionais, não podem ser reduzidas apenas às suas expressões econômicas mas, pelo contrário, devem ser compreendidas no âmbito de um momento de abertura, de indeterminação e de ausência de poder que assume feições diversas, no plano sócio-cultural.

Assim, a exclusão não elimina a presença de processos de integração, aparentemente contraditórios, que caracterizam a vida desses setores jovens empobrecidos mas não miseráveis da sociedade. Esses processos se exprimem nas lógicas que decorrem da inserção juvenil no mundo do consumo, da produção de imagens, símbolos e da mídia. Essas situações podem funcionar como apelos para o consumo que se realiza apenas parcialmente, muitas vezes pelo trabalho precoce ou pelo exercício de atividades ilícitas no mundo da delinquiência e da droga (Zaluar, 1992). Mas os processos subjacentes a este universo das imagens, dos símbolos e da comunicação tendem, como afirma Melucci, a produzir controles difusos da capacidade de expansão do jovem e propiciam definições externas da identidade, reduzindo sua margem de autonomia (Melucci, 1991).

O processo de saída do mundo da infância ocorre na interação contínua com um conjunto de agências socializadoras encarregadas de preparar os imaturos para o exercício pleno da vida adulta.

Na juventude, os laços com a família tendem a se tornar mais difusos ao lado de uma inserção mais forte em outras instituições que pode, muitas vezes, repercutir no próprio padrão socializador desenvolvido pelo grupo familiar de origem. Dentre as agências privilegiadas nesta fase da socialização secundária estaria a escola, encarregada de transmitir os valores sociais mais amplos e de preparar para a divisão social do trabalho.

Em casos como o brasileiro, é preciso considerar que as esferas de socialização advindas do mundo do trabalho cedo penetram e podem influenciar a condição do jovem e interferir tanto na dinâmica familiar como no padrão de interação que ele mantém com o mundo escolar. No entanto, embora a constatação de que a atividade remunerada seja uma realidade para grande parcela dos adolescentes e jovens brasileiros, não se pode atribuir apenas aos 
elevados índices de pobreza as razões para a busca do emprego; o desejo de maior autonomia, a liberdade para decidir sobre seus hábitos de consumo e estilo de vida, ao lado de uma maior atratividade do mercado de trabalho em centros urbanos como São Paulo, são fatores que oferecem estímulos suficientes para o ingresso em uma fase bem precoce da vida (Cervini \& Burger, 1991; Madeira \& Bercovich, 1992; Dauster, 1992).

Muitas vezes a inserção no mundo do trabalho é movida pela pressão familiar, tanto para melhorar o nível de subsistência do grupo quanto para ocupar o tempo ocioso do adolescente ou do jovem, freqüientemente despendido na rua (Vogel \& Mello, 1991). Mas a renda mensal advinda do trabalho, além do auxílio à manutenção familiar, proporciona possibilidades de um tipo especial de consumo não garantido pela família. Essa propensão para o consumo tende a se acentuar na faixa jovem depois dos 14 anos e resulta na adoção de novas indumentárias, discos ou atividades de lazer.

A integração no mercado pela via do consumo nem sempre é valorizada pelos pais, marcados pela ética do trabalho árduo em seu processo de socialização, temerosos dos gastos supérfluos que traduzem o "look" juvenil e suas respectivas formas de consumo do tempo livre ${ }^{7}$. É preciso considerar, no entanto, que a ética do trabalho que permeia alguns vínculos nucleares das relações na família ocorre, principalmente, na figura do "provedor", no interior da rede de relações pessoalizadas e solidárias do mundo da casa. Os estudos realizados em grupos populares urbanos, tanto em São Paulo como no Rio de Janeiro, demonstram que não se verifica o primado do individualismo moderno tal como se observou nas sociedades industriais mais avançadas (Zaluar, 1985; Bilac, 1993).

Por outro lado o reconhecimento de que o trabalho é um elemento que integra a vida dos jovens no Brasil pouco ajuda para a compreensão das relações entre esse mundo e a configuração da identidade. Ou seja, a sociabilidade tecida pela mediação dos vínculos com o mundo do trabalho, extremamente diversificado, pleno de situações de instabilidade, tende a exercer menor força na conformação da identidade do jovem. Tanto a fluidez, a precariedade e a indefinição das relações de trabalho no Brasil, como os seus possíveis efeitos na auto-imagem do trabalhador, afirma Silva (1990), podem contribuir para o enfraquecimento do "orgulho pelo trabalho", produzindo o "orgulho do provedor" cuja ética foi bem analisada por Alba Zaluar (1985) ${ }^{8}$.

O processo de socialização do jovem sob o ângulo da escola produz novo conjunto de relações marcadas pelo seu aspecto tenso e descontínuo.

A primeira expressão dessa incongruência ocorre no desencontro entre as esperanças construídas pelas famílias em torno do valor da escola e as aspirações juvenis, produzidas em um ambiente não mais colorido pela crença nos benefícios imediatos da instrução para a ascensão social e melhoria das condições de vida, tão importantes para a geração anterior.

Para o jovem, este desencontro entre a expectativa inicial, gestada na convivência familiar, e a experiência quotidiana, que nega essas aspirações,
${ }^{7}$ Essa diferença de percepção e eventuais crises no relacionamento familiar não significam necessariamente a existência de um conflito entre gerações que incidiria sobre a oposição reconhecida de modelos culturais de comportamento, como se observou na geração dos anos 60, mais rapidamente afetada pelo processo de modernização. A estruturação de orientações diversas para o comportamento, a partir do consumo ou do trabalho, que podem conviver ou entrar em conflito no âmbito do grupo familiar, certamente demanda investigações mais pormenorizadas sobre o grau em que afeta o processo de socialização secundária e o peso da família na conformação da identidade do jovem.

${ }^{8}$ É preciso reconhecer que as necessidades de consumo, muitas vezes impostas aos jovens, podem interferir nas representações e relações com o mundo das ocupações e da atividade profissional. A predominância de relações tipicamente instrumentais, que enfatizam os benefícios materiais advindos da ocupação, resultariam no menor investimento pessoal e afetivo na própria atividade enquanto aprendizado de um ofício ou etapa de uma carreira. Esse tipo de comportamento foi também observado por Dubet em sua pesquisa sobre os jovens alunos do curso secundário na França (Dubet, 1991). 
${ }^{9} \mathrm{Na}$ sociedade brasileira, as relações entre o mundo das relações pessoais e familiares a casa - e a vida na rua foram analisadas por Roberto DaMatta (1985). Algumas características do universo socializador do mundo da rua há algumas décadas na cidade do Rio de Janeiro são apresentadas por Vanilda Paiva (1992). As relações entre o mundo do crime e a rua são examinadas por Alba Zaluar (1985, 1992 e 1993). é demasiadamente evidente. Ele se expressa no ceticismo frente aos possíveis benefícios resultantes da escolaridade ou, em algumas situações limite, na violência contra os prédios, equipamentos e às vezes professores ou funcionários.

Instala-se, assim, uma relação intermitente com a escola (Madeira, 1986), caracterizada pela exclusão definitiva precoce ou por um eterno retorno que não significa necessariamente freqüência efetiva às aulas ou continuidade nos vários níveis da escolaridade. Para outros segmentos juvenis, aqueles que permanecem e se submetem a uma ação mais contínua do sistema escolar, a sua eficácia socializadora é bastante reduzida além do seu quase absoluto insucesso na transmissão do conhecimento para os setores desprivilegiados da população (Paiva, 1992).

Assim, tanto pela ausência, como pela sua incapacidade em atender às suas aspirações, a escola tende a ocupar um espaço menor no âmbito da socialização dos jovens, sendo incapaz de estruturar relações sociais duradouras e significativas (Dubet, 1991). As referências à escola, quando existem, mesmo positivas, decorrem muitas vezes do trabalho pessoal e das características de personalidade de alguns professores (Guimarães, 1992). Não obstante a atribuição de algum grau de importância às funções socializadoras mais gerais, próprias do sistema de ensino, sobretudo aquelas que dizem respeito à preparação profissional e ao credenciamento, este fato parece orientar somente o nível de algumas frágeis expectativas. E, assim, a instituição escolar pouco contribui para a estruturação efetiva de referências, ao oferecer escassa capacidade de propiciar arranjos que assegurem um conjunto de relações sociais significativas.

Nesse tecido das instituições que recobrem as formas de sociabilidade juvenil, de sua mudança e crise, adquirem um relevo fundamental as dimensões socializadoras do mundo da rua.

De algum modo, a rua se inscreve na sociabilidade urbana, em vários momentos da vida das cidades, mas ela se reveste de especificidades históricas que precisam ser consideradas e examinadas na interação com outras instituições socializadoras ${ }^{9}$.

Nos últimos anos, as ruas de grandes cidades como São Paulo se transformam em local de trabalho e moradia, passam a ser ocupadas por crianças e adolescentes, excluídos da sociedade que lhes nega o direito à vida em família, à escola e, sobretudo, o direito de serem crianças.

Por essas razões, o tema das crianças de rua, ao adquirir sua necessária relevância política e social, acabou por recobrir, no plano da investigação, todas as dimensões da sociabilidade gestada nas áreas públicas da cidade, indiferenciando o próprio espaço urbano.

Mas a rua não é apenas local de trabalho precoce, tornando-se, também, espaço de violência que atinge adolescentes e jovens na interação com o mundo da delinqüência, do consumo de drogas, do crime, das agressões policiais ou de exterminadores. No conjunto dos crimes noticiados pela imprensa no Brasil, durante o ano de 1989, observa-se que São Paulo, em números absolu- 
tos, é a cidade que apresenta maior índice (209 de um total de 457); 78,5\% dos assassinatos visaram à eliminação de pessoas de até 17 anos; tais crimes são praticados principalmente em locais públicos como bares, estabelecimentos comerciais, transporte coletivo, sendo que 50\% são cometidos em logradouros públicos, onde também são deixados os corpos (MNMMR/IBASE/NEV, 1991).

Enfim, não é possível desconhecer as alterações no padrão das relações sociais que ocorrem nas ruas e bairros da cidade, quando o pano de fundo é a agudização da crise social, o crescimento do crime e do tráfico de drogas ao lado da conivência e da corrupção do sistema policial. No entanto esta apropriação perversa não esgota todas as possibilidades de uso do espaço urbano que contempla arranjos diversos em grandes cidades. Ruas e esquinas de um mesmo bairro ou em relação aos espaços do centro traduzem diversas formas de viver, conceber e imaginar o tecido social e o uso do espaço. Territórios menos visíveis no interior das metrópoles acenam para novas modalidades da sociabilidade juvenil: a disseminação dos grupos de RAP na cidade de São Paulo constitui um bom exemplo.

\section{O RAP nas ruas da cidade}

Em pouco tempo o RAP - Rhythm and Poetry - enquanto estilo de música jovem invadiu os meios de comunicação de massa no Brasil e se torna objeto de consumo cultural mais amplo. Embora suas primeiras manifestações tenham ocorrido a partir do início da década de 80 , nos últimos dois anos esse gênero não se limita aos circuitos negros ou populares e passa a fazer parte do campo de preferências dos jovens de classes médias da cidade de São Paulo. Sua batida cadenciada e, sobretudo, as letras que constituem as músicas, combinando em uma feliz junção ritmo e poesia, atraem a população jovem e o próprio mercado de consumo cultural de massas ${ }^{10}$.

Por essas razões, de início é preciso distinguir dois tipos de fenômenos: o primeiro diz respeito ao RAP enquanto gênero musical, consumido pela juventude, em especial negra e trabalhadora, por meio da freqüência aos salões de baile da periferia ou clubes que integram o circuito cultural negro no centro da cidade, pelo consumo de discos e audiência às rádios FMs; o segundo, objeto de análise neste artigo, envolve a disseminação do RAP enquanto prática de produção cultural, não apenas modalidade de consumo, resultando na criação de diversos grupos e na sua integração ao movimento hip-hop. Assim, o RAP será examinado como manifestação jovem, originada nas ruas das cidades, em seus bairros distantes onde vivem os setores mais empobrecidos de São Paulo. Sob esse ponto de vista ele passa a ser entendido como produto da sociabilidade juvenil, reveladora de uma forma peculiar de apropriação do espaço urbano e do agir coletivo, capaz de mobilizar jovens excluídos em torno de uma identidade comum.

Mesmo sendo estilo de música, o RAP não se reduz a um mecanismo habitual da sociedade de consumo ou mercado jovem. A fala cadenciada, a partir de uma base musical semelhante, faz da palavra associada a um ritmo a
${ }^{10}$ Em 1994 a mídia definitivamente consagra o RAP, mediante sua incorporação em filmes publicitários para a TV ou trilhas sonoras de programas de partidos políticos. 
${ }^{11}$ Em São Paulo os RACIONAIS constituem o primeiro grupo que nasce na periferia e alcança repercussão intensa nos circuitos jovens, sendo considerados produtores de um RAP essencialmente político e agressivo, voltado para a denúncia do racismo. Outros, como os ESCOPETAS, participantes de apresentações em salões de bailes na periferia, se consideram desenvolvendo um estilo calcado no humor e na crítica dos costumes.

${ }^{12}$ Depoimento de integrantes dos grupos DMN e RACIONAIS, entrevistados em $1992 \mathrm{e}$ 1993, respectivamente. sua grande força. É preciso falar sobre o que se passa, contar a vida das ruas, seus dilemas, denunciar ou ridicularizar o que ocorre na sociedade, fazer a crítica dos costumes. Esta é uma tônica predominante na produção musical dos rappers, podendo ser traduzida em expressões variadas, pois cada grupo que se forma desenvolve o seu estilo peculiar acentuando o humor ou a sátira, a denúncia política ou o romantismo ${ }^{11}$.

Mas, se o RAP nasce no interior do mundo da exclusão, é preciso considerar que nesse âmbito ele opera um recorte inicial: trata-se da exclusão social associada a uma outra modalidade de exclusão advinda das relações entre as raças. Assim, esse gênero procura articular, nem sempre organicamente, três dimensões: a primeira, mais próxima de suas origens, aponta para as questões específicas que afligem a população negra no interior de uma sociedade marcada pela hegemonia do branco; uma segunda, de caráter social, expressa-se na denúncia das condições de vida das populações trabalhadoras da sociedade; e a terceira aponta para as dimensões excludentes das relações geracionais, remetendo a uma específica forma de discriminação que atinge os jovens, marcados pela estreitas possibilidades de emprego, pelas dificuldades escolares, pelos dilemas presentes no mundo das drogas ou do crime e, sobretudo, porque este setor se tornou o alvo privilegiado da violência policial e de grupos exterminadores.

Assim, a linguagem expressiva que constitui a música RAP recobre a denúncia da dominação entre as raças, da exclusão social e da marginalização dos jovens; combina, em síntese, a condição de ser negro, jovem e excluído.

Duas grandes metas compõem a expressão musical dos grupos e o seu objetivo de atuação, sobretudo daqueles que aparecem com maior vocação política. A primeira incide sobre a questão da identidade negra, voltada para o desenvolvimento da auto-estima, do orgulho de ser preto e da recusa das dimensões de dominação presentes nas relações entre as raças. Essas dimensões não se limitam aos valores impostos pelo branco, mas compreendem atitudes originadas no interior da própria conduta do negro que já se relaciona com o branco na condição de subalterno ou inferior. A segunda meta pode ser traduzida no esforço de informar os jovens para que estes se apropriem do conhecimento necessário para sobreviver, propiciando uma interpretação alternativa dos acontecimentos, uma vez que a mídia, sobretudo a televisão, seria a grande responsável pela conformação das mentalidades e do imaginário juvenil $^{12}$.

As origens jamaicanas e urbanas do RAP, sobretudo nos subúrbios pobres de New York, são reconhecidas por todos os seus participantes. Ao nascer sob a forma de canto e ritmo nas ruas e esquinas da cidade - street players - esse gênero retoma, de modo criativo, a tradição oral dos negros da África Ocidental que entoavam canções nas aldeias (griots). Esta herança continua, nos EUA, com os escravos das plantações sulinas e prisioneiros negros nas primeiras décadas do século XX que, na submissão ao trabalho forçado, cantavam para denunciar e mitigar seu sofrimento (Toop, 1991). A esse 
conjunto de influências pode ser também acrescida a própria tradição oral da cultura popular brasileira, expressa pelos cantadores e poetas repentistas.

Contudo, o RAP opera uma sofisticada fusão cultural, pois mistura uma grande diversidade de velhas raízes culturais da África Ocidental com as mais novas tecnologias advindas do mundo dos aparelhos de som, da acústica e dos “disk-jockeys - os DJs" e "mestres de cerimônia - MCs" (Toop, 1991).

A música RAP, como já foi observado, integra um movimento mais amplo denominado hip-hop, que reúne outras duas manifestações importantes: a dança break, realizada nas ruas e praças da cidade, e o grafite, forma visual de ocupação do espaço urbano. Nos EUA, o grafite como movimento significou a invasão das áreas nobres das grandes cidades por aqueles que viviam segregados nos guetos e subúrbios pobres, que deixavam os sinais visíveis de sua presença através dos muros e paredes pintados; se os brancos de $\mathrm{New}$ York nunca visitaram as partes negras ou hispânicas da cidade, o grafite foi uma espécie de visitação, de invasão simbólica do centro da cidade, encontrada pelos jovens negros e porto-riquenhos (Toop, 1991).

Em São Paulo, o RAP inicialmente surgiu nos salões que animam a noite paulistana no circuito negro e popular dos bairros periféricos. Em meados dos anos 80, os bailes eram em algumas ocasiões especiais animados com grupos norte-americanos, contando com poucos expoentes brasileiros. A freqüência a estes bailes foi, para alguns jovens, o primeiro contato com a música e o início de novas relações de amizade que resultaram, muitas vezes, na formação de grupos.

Mas a música, no final dos anos 80, não se limita aos salões e ocupa as ruas, envolve pequenos grupos nos bairros distantes. Nesse momento, uma dupla via de entrada do jovem para a constituição de um grupo de RAP pode ser observada: o gosto pela música ou pela dança de rua e o espaço das relações de amizade, que o grupo pode solidificar ou ajudar a construir. Integram os grupos, em geral, jovens com mais de 14 anos, embora a presença mais forte ocorra a partir dos 17. Quase todos trabalham, iniciam sua vida profissional como office-boys e apresentam uma relação bastante descontínua com a escola. Dentre aqueles que conseguiram terminar a escola básica, a maioria não chegou a concluir o segundo grau ${ }^{13}$.

Nos bairros periféricos, nos grandes conjuntos habitacionais, as formas de lazer institucionalizadas ou públicas são praticamente inexistentes. Parte do tempo livre, entre a escola e o trabalho, é gasta em uma área nas ruas, que se torna o "pedaço". Para Magnani, o pedaço revela uma peculiar apropriação do espaço urbano que não é típica do mundo da casa e não espelha o anonimato do espaço público ou da rua em seu sentido simbólico mais amplo (Magnani, 1992). Esses pontos de encontro - os pedaços - também caracterizam o modo inicial de apropriação do espaço da rua realizado pelos grupos de RAP: local onde as informações circulam, onde as letras das músicas são trocadas, assim como fitas, discos e revistas. Nesse "pedaço" as músicas são cantadas, a performance e os passos de dança são treinados, sendo, eventual-
${ }^{13}$ Os grupos que se formaram no final dos anos 80 já contam com jovens com mais de 20 anos. São raros aqueles que conseguem sua profissionalização, ou seja, que sobrevivem apenas das apresentações como é o caso dos RACIONAIS. Seus integrantes começaram como office-boys mas, apesar do sucesso, continuam morando na periferia da cidade. Uma parcela se apresenta nos bailes em fins de semana, porém continua a trabalhar, outros sequer se apresentam em salões, se restringindo aos grupos de rua no bairro e a algumas perfomances ou espetáculos em praças públicas. 
${ }^{14}$ Em um encontro realizado em fins de 1992 , em uma escola pública do centro da cidade de São Paulo, estiveram presentes mais de 60 grupos e 15 posses. Uma das posses, localizada em conjunto habitacional no extremo leste da cidade, existente desde 1991, ao comemorar seu segundo aniversário, em abril de 93, registrou a presença de mais de 250 grupos de RAP.

${ }^{15}$ Alguns grupos mais ciosos de sua independência preferem não integrar as posses. Um fenômeno interessante ocorreu na região do ABC paulista, onde rapidamente o RAP se disseminou e provocou a formação de inúmeras posses. O grau de conflitividade foi intenso, provocando a sua dissolução em nome de uma convivência mais pacífica entre os vários grupos existentes.

${ }^{16}$ É muito comum a prática de concursos nos bailes para os grupos emergentes, pois os vencedores acabam por conseguir a possibilidade de gravação de uma música numa coletânea que integra um novo disco produzido por gravadoras de pequeno porte.

${ }^{17}$ Esta distribuição das atividades e sua denominação foi realizada por um membro de uma das posses entrevistadas, Conceitos de Rua, na zona sul da cidade. mente, realizadas algumas apresentações.

Há uma enorme diversidade de grupos criados que escapa a qualquer forma de recenseamento para se aferir a magnitude do fenômeno em São Paulo, embora a cidade certamente conte com mais de 1000 grupos $^{14}$. Mas essa magnitude não pode ser medida apenas pelo gosto musical ou pela freqüência aos bailes nos finais de semana, que reúnem mais de 40000 jovens (Revista da Folha, 17/4/1994). Ela envolve a própria experiência de criação musical, de constituição do grupo e do auto-reconhecimento na formulação de uma identidade coletiva enquanto "rapper" que pode resultar em estratégias mais ou menos organizadas de ação.

Muitas vezes o "pedaço" no bairro pode ganhar a feição de um território, que exprime uma intervenção mais ampla e coletiva, mediante a formação das posses ou "crew" grupos (às vezes chegam a 20 grupos com 3 a 5 membros cada) e busca ações mais estruturadas. A posse no Brasil, de acordo com seus integrantes, difere da crew norte-americana, formada para potencializar sobretudo a ação musical dos grupos, ao lado de algumas atividades comunitárias subsidiárias do interesse principal: shows beneficentes para creches ou moradores do bairro. A peculiaridade brasileira residiria no arco mais amplo de atividades, no seu caráter político e na sua preocupação com os aspectos de caráter organizativo.

Em São Paulo as posses definem tarefas que devem ser realizadas pelos seus membros. De modo geral poderiam ser caracterizados três objetivos, nem sempre presentes integralmente ou com a mesma intensidade. $\mathrm{O}$ primeiro, de caráter artístico, visa potencializar a capacidade de produção de músicas e de apresentações não restritas ao bairro, em suas ruas e praças, mas no circuito dos salões da periferia; enfim busca-se maior visibilidade artística. Neste escopo procuram, também, investir na qualidade de sua produção musical para conseguir a gravação de discos em gravadoras alternativas e conseguir a afirmação dos grupos que fazem parte da posse. Como decorrência, as atividades de comunicação ou "empresariais" são importantes, não só para abrir novos contatos, divulgar o trabalho realizado mas, também, para aumentar o poder de interferência do grupo nas redes musicais alternativas ${ }^{16}$.

Essa busca de visibilidade gera certa competição entre os grupos, que lutam por sua afirmação. Para Toop esta competição constituiria o coração do movimento hip-hop e poderia ser considerada elemento positivo, pois não só limitaria o desenvolvimento da violência e o refúgio nas drogas no seu âmbito de ação, mas - e este seria o seu aspecto fundamental - incentivaria uma atitude constante de criação e de invenção a partir de recursos ou meios materiais bastante limitados (1991).

Outras duas modalidades de ação da posse no Brasil podem ser caracterizadas como comunitárias e políticas ${ }^{17}$. As ações comunitárias seriam aquelas desenvolvidas no interior do território compreendido pela posse e podem significar a apresentação de espetáculos cujo ingresso é uma contribuição em agasalhos ou alimentos, dependendo da campanha a ser empreendida. A 
destinação de tais eventos é diversa: amigos ou demais desempregados do bairro, crianças doentes que necessitam de recursos para tratamento, cobertores para os pobres, etc. Outras atividades comunitárias estariam dirigidas, segundo alguns, para jovens consumidores de drogas de modo a criar alternativas dentro da própria posse que sejam capazes de atraí-los. As ações políticas estariam mais próximas daquelas práticas típicas do movimento negro, mediante a participação em manifestações políticas mais amplas como passeatas, organização de cursos e debates.

A formação da posse envolve o reconhecimento de um líder escolhido para representá-la, aquele que fala em nome de todos. Algumas vezes, seus integrantes escolhem um padrinho ou madrinha, em geral uma figura idosa do bairro que, de algum modo, simboliza os objetivos que os une. De qualquer modo a "crew" exige um conjunto de comportamentos e de atitudes que permitem estabelecer elos mais permanentes de solidariedade. A admissão de neófitos às vezes é precedida de algumas exigências que assegurem a adesão e lealdade aos objetivos estabelecidos.

Se as galeras ou tribos urbanas aparecem com um potencial altamente conflitivo intergrupos, o RAP não apresenta de imediato essa característica, embora algumas disputas com outros agrupamentos possam ocorrer. No âmbito dos bairros, a presença de grupos de carecas, caracterizados por uma pregação conservadora e freqüentemente racista, pode provocar algumas desavenças, mas às vezes uma certa negociação permite o estabelecimento de políticas de boa vizinhança. Entre os rappers os conflitos também são freqüentes e podem se estabelecer em torno de divergências quanto às formas de conduta, o estilo e a qualidade da produção. Mas estas questões ocorrem no âmbito de uma solidariedade muito forte no interior de cada grupo e o reconhecimento da liberdade do outro de escolher o seu próprio caminho. Algumas vezes as concepções diversas, dotadas de algum grau de antagonismo, são expressas na composição de letras cujo conteúdo estabelece uma espécie de duelo verbal agressivo entre os grupos ${ }^{18}$.

Em São Paulo, mediante o apoio dos movimentos negros, o RAP tenta uma ação mais articulada pela publicação de revista e desenvolve atividades como oficinas em centros de lazer, debates em escolas e espetáculos em bairros, nas ruas ou praças. Promovem cursos e conferências para integrantes dos grupos, marcando, algumas vezes, presença orgânica em manifestações políticas mais amplas, sobretudo aquelas ligadas à causa negra ${ }^{19}$.

\section{RAP, sociabilidade e espaço urbano}

A disseminação dos grupos de RAP em São Paulo chama a atenção para dois aspectos importantes das práticas culturais e da sociabilidade no espaço urbano das grandes cidades.

De um lado é preciso considerar que essas ações nascem no âmbito de grandes cidades que, pela natureza do seu desenvolvimento, tendem a produzir processos de perda das referências tradicionais na construção de identi-
${ }^{18} \mathrm{O}$ caráter menos conflitivo das crews frente às tradicionais gangues urbanas decorre, segundo Toop, dos elementos competitivos característicos do RAP nos EUA (1991). Há uma linha feminina no RAP em São Paulo que critica o "machismo" dos grupos masculinos. Essas divergências foram tratadas no conjunto das músicas compostas pelas "facções" em disputa. A existência de grupos femininos abre outras perspectivas de análise, pois enquanto fenômeno, o RAP é predominantemente masculino, chegando mais tardiamente a mobilizar mulheres jovens que, no entanto, consideram o movimento portador de características "machistas", comuns no interior das relações sociais mais amplas. Não é estranho, por exemplo, que nas performances de rua as mulheres sejam, na maior parte das vezes, apenas observadoras.

${ }^{19}$ As relações entre o movimento RAP e os grupos organizados de militantes negros merecem uma análise especial que não pode ser desenvolvida nos limites deste artigo. 
dades. No entanto, para Canclini, a homogeneização do consumo e da sociabilidade propiciada pelos formatos comuns com que se organizam os serviços e demais instituições do mundo urbano não apagam totalmente as particularidades (Canclini, 1993).

Se há uma desestruturação de algumas das experiências citadinas pela atomização das práticas simbólicas e declínio de alguns centros comuns de consumo como cinema e teatro, os grupos e bandos juvenis compensam "a atomização e a desagregação das grandes urbes, oferecendo a possibilidade de pertencimento aos grupos: ante a perda de expectativas em relação à escola e a estreiteza do mercado de trabalho, nascem outra formas de socialização e de acesso aos bens de consumo" (Canclini, 1993). Os bandos juvenis levam até a exasperação os enfrentamentos interculturais, as disputas pelos territórios e seu controle sócio-político; eles atestam a multiplicidade irredutível de linguagens e estilos de vida, de estratégias de sobrevivência e de comunicação nas grande cidades.

Se o RAP tem suas origens nas relações primárias dos grupos de amizade e suas práticas culturais no bairro permitem a construção de identidades coletivas no interior de um processo de segmentação e de pulverização das ações, esta experiência não pode ser designada apenas como produto da cultura local. A relação entre este nível e o global ganha nova figuração com o RAP.

Em sua particularidade, o RAP paulista articula-se a patamares de elaboração simbólica que não estão circunscritos às fronteiras regionais ou nacionais: há uma profunda interação com a produção internacional, sobretudo norte-americana. As informações e material escrito circulam rapidamente, bem como fitas e discos que veiculam essa produção. Ser "rapper" significa compartilhar esse universo global de significados, cujo alicerce comum se estrutura na identidade negra, independente do país de origem.

Por essas razões o RAP também pode ser considerado um produto da cultura enquanto fenômeno de globalização (Ortiz, 1993) sem dissolver, no entanto, as particularidades ${ }^{20}$. Os rappers não se contentam em atingir o público imediato com o qual se defrontam no seu "pedaço", território ou bairro. Querem e disputam a possibilidade de entrar no circuito do consumo e da circulação de bens culturais. Seu alvo é o grande público - jovem, negro, excluído não apenas o que está mais próximo no âmbito das relações primárias do bairro. Lutam e empreendem ações voltadas para um público amplo, querem divulgar sua mensagem e constituir uma via alternativa de informação e conhecimento, constituindo os meios de comunicação de massa em poderosos adver-

${ }^{20}$ Para Ortiz (1993), a globalização da cultura pode significar um processo de desterritorialização. Estas não seriam as dimensões presentes no desenvolvimento do RAP em São Paulo. sários. Não se gesta, no entanto, uma espécie de rejeição à tecnologia audiovisual e à indústria cultural; trata-se de criar, se possível mediante a utilização de todos os recursos da moderna tecnologia, uma capacidade de interpretação e de produção de significados que se contraponham à mídia.

Entretanto, a superação de fronteiras nacionais, o seu caráter globalizante e a busca de interação com a indústria cultural não desterritorializam o RAP. Como parte essencial da produção radica-se na formulação das 
letras, na força da palavra que deve ser compreendida, ocorre o estímulo às experiências vividas na rede de relações mais imediatas: há um enorme apelo para a criatividade na medida em que todos os grupos se caracterizam por compor suas próprias músicas e desenvolverem seu estilo particular, de modo a distinguí-los dos demais. As letras, mediante sua poesia, devem espelhar o aquiagora de quem vive a realidade do mundo da rua, do bairro, da cidade e, nesse plano, o RAP volta a ter uma dimensão específica, particular e até nacional. As músicas são cantadas em português, devem falar da violência policial, das crianças e do extermínio, da ausência dos direitos humanos e da cidadania, cenas do quotidiano das grandes cidades brasileiras.

Por outro lado é preciso também levar em conta que a forma de apropriação do espaço urbano, característica do RAP, rompe com algumas dicotomias, dentre elas a idéia de uma segregação incontornável daqueles que vivem na periferia frente ao centro da cidade.

Embora os grupos de RAP nasçam no interior da sociabilidade de rua que constitui o pedaço no bairro pobre e periférico, eles protagonizam possibilidades diversas de mobilidade espacial em direção ao centro, facilitada pela malha de transportes coletivos urbanos.

O uso do espaço urbano no centro da cidade adquire feições diversas. De um lado porque os "pedaços" frequientados não são produto de uma rede comum ou informal de relações de amizade. Os freqüentadores do mesmo pedaço no centro, como afirma Magnani, "se reconhecem enquanto portadores dos mesmos símbolos, que remetem a gostos, orientações, valores, hábitos, consumo e modos de vida semelhantes" (Magnani, 1992). São essas as razões que determinam o acesso a determinados pontos de encontro.

Em São Paulo, dois espaços delimitados atraem os rappers. O primeiro é uma galeria de lojas no centro da cidade, caracterizada pela venda de produtos e prestação de serviços voltados para o consumo juvenil. Essa galeria, no entanto, compõe-se de espaços que combinam usos diversos, ou seja, ela é constituída de vários pedaços que convivem sem necessariamente se misturar. Desse modo, se há o pedaço dos adeptos do rock, heavy metal ou punk, o seu subsolo é totalmente ocupado pelo consumo e socialização de produtos da cultura negra: a música RAP e demais gêneros, os cabeleireiros black, as roupas típicas como bonés, tênis de cano alto, bermudas ou calças largas, etc. Do mesmo modo, uma praça próxima à estação do metrô no centro histórico, o Largo S. Bento, se caracteriza por um tipo especial de apropriação realizado pelo movimento hiphop. Nessa praça ocorre o encontro espontâneo, sobretudo nos finais de semana, de vários grupos que treinam sua performance, dançam e cantam. Ela é também o local escolhido para apresentação de eventos artísticos, reunindo público bastante numeroso nessas ocasiões ${ }^{21}$.

A apropriação de alguns espaços no centro das cidades, como afirma Routleau-Berger, traduz as microculturas jovens, expressas não apenas na periferia que é o seu lugar de moradia. No centro urbano, esses lugares exprimem os modos de negociação identitária, são "espaços que fazem periferia no cen-
${ }^{21}$ Esta é a descrição do antropólogo que busca caracterizar os pedaços e trajetos a partir de um passeio pelo centro histórico da cidade de São Paulo: "do largo São Bento desce-se para a estação do Metrô. Espaço moderno, contrastando com o entorno da superfície. Além do vaivém dos passageiros, um grupo se destaca, já que lá está dançando. É um bando de adolescentes, hip hops, totalmente à vontade em sua dança-ginástica-performance: só garotos, as poucas meninas apreciando, os mais destros ocupando o espaço central numa sequiência ordenada, enquanto os 'aprendizes' exercitam-se quase em isolamento, num canto" (Magnani, 1992). 
tro", espaços de trânsito que garantem transições sociais e espaciais para os jovens na cidade, espaços que dão um sentido positivo às situações de precariedade (Routleau-Berger, 1988).

Finalizando, é preciso ainda apontar duas formas de encontro de espaços sociais diferentes com as quais se defrontam alguns grupos de RAP na cidade de São Paulo, traduzindo outras apropriações e conflitos por eles desencadeados, novas possibilidades e, também, novos limites.

A primeira diz respeito a algumas das instituições públicas presentes no espaço urbano, sobretudo a rede de escolas. Em grande parte dos bairros pobres da cidade, as unidades de ensino são os únicos aparatos que podem proporcionar alguma atividade cultural ou de lazer para a população. Em geral, os estabelecimentos oferecem poucas possibilidades de interação com os grupos de jovens, sobretudo em suas horas de tempo livre, permanecendo fechadas nos fins de semana ou abertas apenas para algumas atividades esportivas organizadas espontaneamente pelos moradores. Não obstante os esforços empreendidos por alguns governos em estabelecer por meio de políticas públicas um patamar diferenciado de uso dos espaços escolares, até mesmo para atenuar a violência contra os prédios, não houve por parte do conjunto da rede, a não ser em caráter excepcional ou episódico, uma redefinição profunda de um tipo de relação historicamente construída. Uma longa trajetória de distanciamento, de relações difíceis e conflituosas com os seus usuários, caracteriza a existência das escolas públicas nos bairros periféricos da cidade de São Paulo (Sposito, 1993a; 1993b).

Ex-alunos ou ainda freqüentadores das escolas públicas, os membros dos grupos de RAP, de algum modo, reconhecem a importância do universo escolar, porém em um plano simbólico diferente. Enquanto espaço institucional percebem sua importância para utilização das dependências e instalações elétricas em reuniões e ensaios, capazes de garantir as atividades artísticas, em um ambiente marcado pela enorme precariedade material. Percebem, também, a escola enquanto via privilegiada de acesso aos alunos, realizando apresentações e debates para divulgar sua mensagem, sempre que alguma oportunidade se apresenta.

Mas outros significados vão sendo incorporados nesse processo. Embora não encontrem na escola reais possibilidades de assimilação do conhecimento e não construam expectativas de ascensão profissional mediante a escolaridade, realizam uma espécie de reapropriação imaginária do universo escolar. Nesta trajetória reiteram a necessidade do rapper manter-se "bem informado" e, portanto, valorizam um atitude de busca daquele conjunto de saberes supostamente oferecidos pelo ensino. Escola e conhecimento se tornam importantes porque assegurariam o desenvolvimento do RAP, que depende da apropriação e do domínio de informações: "Geralmente os rappers cantam sobre o que sabem e se o conhecimento é limitado, o RAP eventualmente será limitado"22.

A sua constituição como sujeitos, portadores de uma identidade co- 
mum, é o elemento que facilita essa relação com o universo escolar e o seu espaço simbólico, ao mesmo tempo que o redefine. Deixam de ser apenas jovens moradores do bairro, alunos ou ex-alunos da escola, fragmentados, dispersos sem nenhum poder de negociação ou barganha. São os "rappers" que buscam interação, grupo que compartilha uma auto-imagem não mais marcada pelo medo, pela humilhação ou pelo estigma da marginalidade.

A eficácia dessa interação é variada, submetida, em grande parte, às orientações de diretores que ainda detêm o poder de controle do uso do espaço escolar. Não obstante as descontinuidades existentes e as dificuldades no estabelecimento dessa interlocução, o horizonte que se abre é ao menos promissor de uma nova forma de interação do universo escolar com a cultura e as práticas jovens que nascem na rua ${ }^{23}$.

Mas o encontro de espaços que traduzem relações sociais diversas não se esgota no mundo das instituições, dentre elas a escola pública. A disputa na apropriação de territórios nos bairros e o nascimento de um ator coletivo que busca definir seus objetivos, ao oferecer uma alternativa de informação e de conduta para os jovens - seus pares - desvelam adversários poderosos.

Em bairros caracterizados pelos altos índices de violência, os jovens integrantes dos grupos, que estão nos pedaços, nas esquinas das ruas, são "confundidos" com marginais e, portanto, submetidos à violência policial ou de justiceiros, cuja intervenção às vezes é solicitada por moradores ou comerciantes do bairro.

Os rappers podem também se defrontar com outros grupos que ocupam os territórios do bairro, as quadrilhas que disputam as "bocas de fumo" ou pontos destinados ao tráfico de drogas.

Neste embate alguns jovens chegam a sofrer ameaças ou tornam-se vítimas da violência e são assassinados. O espaço urbano deixa de ser locus de disputa e negociações entre os vários agrupamentos que lutam por sua apropriação e se torna palco da guerra onde vale apenas a lei do mais forte que detém o poder das armas (Zaluar, 1993). Diante desse quadro, muitas vezes o silêncio - que oculta a palavra, a força do RAP - e o retraimento para o espaço privado da casa são as estratégias possíveis na luta pela sobrevivência.

As grandes cidades, como São Paulo, oferecem planos diversos de análise, se considerarmos a multiplicidade de relações sociais que nela se descortinam. O exame de uma das formas de apropriação do espaço urbano, aquelas que traduzem a sociabilidade juvenil, pode contribuir para avaliar a magnitude dos desafios que afetam as condições e a qualidade de vida nas metrópoles.

Como afirma Melucci, os jovens são um espelho da sociedade inteira, uma espécie de paradigma dos problemas cruciais dos sistemas complexos: tensões entre expansão das chances de vida e controle difuso, entre possibilidade de individuação e definição externa da identidade. Assim a mobilização juvenil torna-se elemento revelador, trazendo à luz as demandas profundas, os problemas e as tensões que percorrem toda a sociedade (Melucci, 1991).
${ }^{22}$ Frases do encarte do último LP do grupo Public Enemy.

${ }^{23}$ No segundo semestre de 1992, dois grupos de RAP - RACIONAIS e DMN - realizaram apresentações seguidas de debates em 37 escolas públicas municipais como parte de um conjunto de iniciativas destinadas a aproximar a escola de seus usuários. A conjuntura favorável, propiciada por uma administração municipal progressista, certamente facilitou o desenvolvimento da atividade, que foi interrompida em janeiro de 1993, com a posse do novo governo (Sposito, 1993b). 
UNITERMS:

juvenilia, urban life, cultural activities, street players
SPOSITO, Marilia Pontes. Juvenile sociability and the street: new conflicts and collective action in the city. Tempo Social; Rev. Sociol. USP, 5(1-2): 161-178, 1993 (edited in nov. 1994).

ABSTRACT: New forms of collective action spring up in the realm of urban life and feature as main actors the young dwellers of the outskirts of cities like São Paulo (Brazil). Brought about from the sociability in the world of the streets, these forms of action structure the young actors around various trends which may result in the formation of gangs, mobs and racist groups - the skinheads - or groups which gather round activities of self expression like music. As from the mid 80 s one has seen the springing up and spreading of RAP music groups (Rhythm and Poetry). By means of dance and music, which is carried out in the streets, RAP gathers mostly the poor young black people and points out cultural exclusion, police violence and discrimination at work and school.

\section{REFERÊNCIASBIBLIOGRÁFICAS}

BILAC, Elisabete Dória. (1993) A família e a fragmentação do social. Natureza, História e Cultura. Cadernos de Sociologia. Porto Alegre, PPGS/UFRGS.

BRANT, Vinicius (coord.). (1989) São Paulo. Trabalhar e viver. São Paulo, Brasiliense.

Braslawsky, Cecilia. (1985) Juventud y sociedad en la Argentina. Santiago, CEPAL.

Camargo, Candido Procópio. (1976) São Paulo 1975. Crescimento e Pobreza. São Paulo, Loyola.

Canclini, Nestor. (1993) Los desafios de las megaciudades a las politicas culturales. (mimeo). Texto apresentado no XIII Congresso Internacional de Antropologia, México, agosto.

Cervini, Ruben \& Burger, Freda. (1991) O menino trabalhador no Brasil urbano dos anos 80. In: O trabalho e a rua: crianças e adolescentes no Brasil urbano dos anos 80. São Paulo, UNICEF/FLACSO/ CBPIA/CORTEZ.

Costa, Márcia Regina. (1993) Os “carecas do subúrbio”. Rio de Janeiro, Vozes.

DAMattA, Roberto. (1985) A casa e a rua. São Paulo, Brasiliense.

DAuster, Tania. (1992) Uma infância de curta duração: trabalho e escola. Cadernos de Pesquisa. São Paulo, Fundação Carlos Chagas, nº 82, agosto. 
Dubet, François. (1991) Les lycéens. Paris, Seuil.

Fundação SEAde. (1993) Pesquisa das condições de vida na região metropolitana de São Paulo: principais resultados. São Paulo.

GoHN, Maria da Glória. (1982) Reivindicações populares urbanas. São Paulo, Cortez.

. (1985) A força da periferia. Rio de Janeiro, Vozes.

. (1991) Movimentos sociais e luta pela moradia. São Paulo, Loyola.

Guimarães, Eloísa \& Paula, Vera. (1992) Cotidiano escolar e violência. In: Zaluar, Alba (org.). Violência e educação. São Paulo, Livros do Tatu/Cortez.

JACOBI, Pedro. (1989) Movimentos sociais e políticas públicas. São Paulo, Cortez.

KrischKe, Paulo (org.). (1984) Terra de habitação X Terra de espoliação. São Paulo, Cortez.

KOWARICK, Lúcio (org.). (1988) As lutas sociais e a cidade. Rio de Janeiro, Paz e Terra.

Lefebvre, Henri. (1978) De lo rural a lo urbano. Barcelona, Peninsula.

LoPES, Juarez Brandão \& GotTschalk, Andréa. (1990) Recessão, pobreza e família - a década pior do que perdida. São Paulo em Perspectiva. São Paulo, Fundação SEADE, vol. 4, no 1 .

MadeIRA, Felicia. (1986) Os jovens e as mudanças estruturais na década de 70: questionando pressupostos e sugerindo pistas. Cadernos de Pesquisa. São Paulo, Fundação Carlos Chagas, no 58, agosto.

Madeira, Felicia \& Bercovich, Alicia. (1992) A “Onda Jovem” e seu impacto na População Economicamente Ativa de São Paulo. Planejamento e políticas públicas. Instituto de Pesquisa Econômica Aplicada, no 8 , dezembro.

MaGnani, José Guilherme. (1992) Da periferia ao centro: pedaços e trajetos. Revista de Antropologia. São Paulo, Departamento de Antropologia, FFLCH/USP, vol. 35.

Mannheim, Karl. (1954) Diagnostic of our time. London, Routledge \& Kegan.

MelucCI, Alberto. (1991) L'invenzione del presente. Bologna, il Mulino.

MNMMR/IBASE/NEV. (1991) Vidas em risco: assassinatos de crianças e adolescentes no Brasil. Rio de Janeiro.

OrTiz, Renato. (1993) Cultura e mega-sociedade mundial. Lua Nova. São Paulo, n오 $28 / 29$.

PAIVA, Vanilda. (1992) Violência e pobreza: a educação dos pobres. In: ZaLUAR, Alba (org.). Violência e educação. São Paulo, Livros do Tatu/Cortez. 
RAMA, Germán. (1990) La situación de la juventud y los problemas de la insércion en la sociedad. Final do século: desafios da educação na América Latina. São Paulo, CLACSO/REDUC/ CORTEZ.

RoutLeAu-Berger, Laurence. (1988) Des micro-cultures et des jeunesses au centre et à la péripherie de l'espace urbain. La culture des jeunes de banlieues. Document de L'Institut National de la Jeunesse, $\mathrm{n}^{\mathrm{o}} 4$.

SiLvA, Luís Antonio Machado. (1990) A (des)organização do trabalho no Brasil urbano. São Paulo em Perspectiva. São Paulo, Fundação SEADE, vol. $4, \mathrm{n}$ os $3 / 4$.

Singer, Paul \& Brant, Vinícius (orgs.). (1980) São Paulo: o povo em movimento. Rio de Janeiro, Vozes/CEBRAP.

Sposito, Marilia Pontes. (1992) Indagações sobre a educação de jovens filhos de migrantes. Travessia, São Paulo, vol. 5, no 12. . (1993a) A ilusão fecunda: a luta por educação nos movimentos populares. São Paulo, EDUSP/HUCITEC.

. (1993b) Violência coletiva, jovens e educação: dimensões do conflito social na cidade. (mimeo). Texto apresentado no XIII Congresso Internacional de Antropologia, México, agosto.

Toop, David. (1991) Rap Attack 2. New York, Serpent's Tail.

Vogel, Arno \& Mello, Marco Antonio. (1991) Da casa à rua: a cidade como fascínio e descaminho. In: $O$ trabalho e a rua: crianças e adolescentes no Brasil urbano dos anos 80. São Paulo, UNICEF/ FLACSO/CBPIA/CORTEZ.

Zaluar, Alba. (1985) A máquina e a revolta. Rio de Janeiro, Paz e Terra. . (1992) Nem líderes nem heróis: a verdade da história oral. In: (org.). Violência e educação. São Paulo, Livros do Tatu/ Cortez.

. (1993) Quando o malandro dança. Natureza, História e Cultura. Cadernos de Sociologia. Porto Alegre, PPGS/UFRGS. 